https://helda.helsinki.fi

\title{
Current status of the multinational Arabidopsis community
}

\section{The Multinational Arabidopsis Steering Committee}

2020-07-01

The Multinational Arabidopsis Steering Committee, Parry , G, Provart , N J \& Wrzaczek, M 2020 , ' Current status of the multinational Arabidopsis community ', Plant Direct, vol. 4 , no. 7 , e00248 . https://doi.org/10.1002/pld3.248

http://hdl.handle.net/10138/340647

https://doi.org/10.1002/pld3.248

cc_by

publishedVersion

Downloaded from Helda, University of Helsinki institutional repository.

This is an electronic reprint of the original article.

This reprint may differ from the original in pagination and typographic detail.

Please cite the original version. 


\title{
Current status of the multinational Arabidopsis community
}

\author{
Geraint Parry $^{1}$ | Nicholas J. Provart ${ }^{2}$ | Siobhan M. Brady ${ }^{3}$ | Baris Uzilday ${ }^{4}$ | \\ The Multinational Arabidopsis Steering Committee ${ }^{2}$
}

\author{
${ }^{1}$ School of Biosciences, Cardiff University, \\ Cardiff, United Kingdom \\ ${ }^{2}$ Department of Cell and System Biology/ \\ Centre for the Analysis of Genome Evolution \\ and Function, University of Toronto, \\ Toronto, Canada \\ ${ }^{3}$ Department of Plant Biology and Genome \\ Center, University of California, Davis, USA \\ ${ }^{4}$ Department of Biology, Faculty of Science, \\ Ege University, Izmir, Turkey

\section{Correspondence} \\ Geraint Parry, GARNet, School of \\ Biosciences, Cardiff University, Cardiff, \\ United Kingdom. \\ Email: geraint@garnetcommunity.org.uk \\ Nicholas J. Provart, Department of Cell and \\ System Biology/Centre for the Analysis of \\ Genome Evolution and Function, University \\ of Toronto, Toronto, Canada. \\ Email: nicholas.provart@utoronto.ca \\ Siobhan M. Brady, Department of Plant \\ Biology and Genome Center, University of \\ California, Davis, CA, USA. \\ Email: sbrady@ucdavis.edu \\ Funding information \\ UKRI-BBSRC grant, Grant/Award Number: \\ BB/M004376/1; HHMI Faculty Scholar \\ Fellowship; The Scientific and Technological \\ Research Council of Turkey, Grant/Award \\ Number: $118 Z 137$
}

\begin{abstract}
The multinational Arabidopsis research community is highly collaborative and over the past thirty years these activities have been documented by the Multinational Arabidopsis Steering Committee (MASC). Here, we (a) highlight recent research advances made with the reference plant Arabidopsis thaliana; (b) provide summaries from recent reports submitted by MASC subcommittees, projects and resources associated with MASC and from MASC country representatives; and (c) initiate a call for ideas and foci for the "fourth decadal roadmap," which will advise and coordinate the global activities of the Arabidopsis research community.
\end{abstract}

\section{KEYWORDS}

Arabidopsis thaliana, collaboration, Research Network, roadmap
The multinational Arabidopsis research community is highly collaborative. This has been demonstrated through global efforts to publish the Arabidopsis genome sequence in 2000; the long-term support for the three international stock centres in the United States, United Kingdom and Japan; and in the development of community-facing informatics resources such as The Arabidopsis Information Resource (TAIR), the Bio-Analytic Resource for Plant Biology (BAR), the Munich
Information Centre for Protein Sequences (MIPS), the International Arabidopsis Informatics Consortium (IAIC), and Araport.

The Multinational Arabidopsis Steering Committee (MASC) has represented this global community through its joint oversight of the annual International Conference on Arabidopsis Research (ICAR); production of a MASC annual report ${ }^{1}$; and preparation of a series of decadal roadmaps that have helped coordinate the future

*A complete list of The Multinational Arabidopsis Steering Committee can be found in the Appendix at the end of the manuscript.

White paper submitted on behalf of the Multinational Arabidopsis Steering Community.

This is an open access article under the terms of the Creative Commons Attribution License, which permits use, distribution and reproduction in any medium, provided the original work is properly cited.

(c) 2020 The Authors. Plant Direct published by American Society of Plant Biologists and the Society for Experimental Biology and John Wiley \& Sons Ltd 





\section{3 | UPDATE ON INTERNATIONAL PROJECTS WITH A FOCUS ON ARABIDOPSIS}

A primary example of the collaborative nature of the global Arabidopsis research community is the success of the international stock centres (Nottingham Arabidopsis Stock Centre [NASC], The Arabidopsis Biological Research Center [ABRC] and the RIKEN Bioresource Centre). Despite reporting a downward trend over the past decade, the ABRC distributes annually almost twice as many seed stocks as NASC (190K versus $100 \mathrm{~K})$. However, NASC has seen increases over the past few years that undoubtedly reflects that it is the go-to stock centre for orders from China. The continued success of the stock centres relies on donations of plant material (mostly seeds) from the community and NASC reports that over the past few years German scientists have provided their largest number of donations.

Despite losing government funding over 5 years ago, TAIR continues its excellent biocuration services via an innovative and successful subscription model (Reiser et al., 2016). TAIR has expanded its operations to include collaborations with both PhyloGenes (www. phylogenes.org), a new resource that facilitates inference of gene function based on phylogenetic relationships, and with the open access MicroPublications journal (https://www.micropublication.org/) that facilitates the publication of brief, novel findings, negative and/ or reproduced results that may lack a broader scientific narrative. Each week TAIR loads 50-90 papers with the term "Arabidopsis" in the title or abstract into their curation queue. This includes a steady number of papers that report on new functions for previously characterized genes and an increase in the number of papers that describe high-throughput experiments and contain large datasets. For a variety of reasons, curating from some papers can be challenging so TAIR have produced a document to advise researchers how to make the details of their research more "findable" (https://conf.arabi dopsis.org/pages/viewpage.action?pageld=22807345).

Oversight of the Arabidopsis informatics strategy has largely fallen to the International Arabidopsis Informatics Consortium (IAIC), which was funded by the NSF until 2020. In 2018 IAIC hosted a workshop in St Louis and its "take home" recommendation was for the establishment of a centralized "annotation authority" to advise on submissions from groups for new gene names across the Arabidopsis pangenome, to establish a consistent naming scheme, to distribute this format regularly and frequently, and to encourage its adoption (International Arabidopsis Informatics Consortium, 2019). This article also recommends community-established guidelines and standards for data and metadata formats alongside a searchable, central repository for analysis and visualization tools (such as https://conf.arabidopsis.org/display/COM/Resources). Fortunately, the implementation of these recommendations will be facilitated by a closely linked international community and will undoubtedly be a topic discussed for inclusion within the next roadmap.

The BAR resource continues to be a central hub for researchers to interrogate and visualize their expression data. In addition to its expansion to include data from many other plant species, the BAR is far more than

just an "eFP Browser." The BAR website includes access to a broad set of genomic tools and widgets that have a focus on the analysis of Arabidopsis datasets. The BAR has obtained funding from Genome Canada that will allow the development of a custom "eFP" view in ePlant for a researcher's own RNA-seq data as well as the initiation of several new ePlants.

The International Plant Phenotyping community provides excellent links between Arabidopsis research and that conducted in other plant species. The MASC annual report includes brief updates from the International Plant Phenotyping Network (IPPN), European Plant Phenotyping Network (EPPN) and European Infrastructure for Plant Phenotyping (EMPHASIS). An important general feature of these networks is that they host regular calls for applications from researchers to access phenotyping infrastructures where they do not have them available at their home institutions. The European Infrastructure for Plant Phenotyping (EMPHASIS) project is arguably the most interesting development in this area. When it becomes fully operational in 2022 EMPHASIS will place plant phenotyping in a position to obtain centralized European funding through similar mechanisms to those that support other large European infrastructure projects such as the Square Kilometre Array for radio astronomy (although plant phenotyping is much cheaper, http://roadmap2018.esfri.eu/).

\section{4 | MASC COUNTRY UPDATES}

The MASC Country Reports provide an overview on the progress of Arabidopsis research on a national scale, cataloguing important publications, new software tools and community resources. Currently, 34 countries with a MASC representative are asked to submit an annual report and 29 of these were able to submit reports in 2020, notwithstanding shutdowns related to the COVID-19 pandemic. We include some country highlights here.

China is an interesting case study as its country report states that "Arabidopsis is the model plant of choice to many groups. However, only a small portion of these labs is solely dedicated to Arabidopsis research or using [it] as the main model plant.... A major reason behind [this] would be the current funding priority. Whereas there are dedicated grants to basic and applied research in maize, rice, wheat, and virtually each every minor crop, there are no such funding programs towards Arabidopsis research."

Although there is somewhat of a plateau in the number of global Arabidopsis publications over the past 5 years, this is not an even trend across all countries (Figures 1 and 3 ). While numbers of publications on Arabidopsis are steady or falling in some countries, this is offset by the increase in publications coming from Chinese labs, which shows no slow-down since trending upward a decade ago. This indicates that Chinese researchers are pragmatically continuing to leverage Arabidopsis as a model plant despite a lack of dedicated funding for Arabidopsis research per se.

MASC Country representatives provide an opinion on the current status of Arabidopsis research in their countries. It is challenging to obtain a consistent metric for these evaluations as different countries will view their situation from different starting positions. For example, the United 


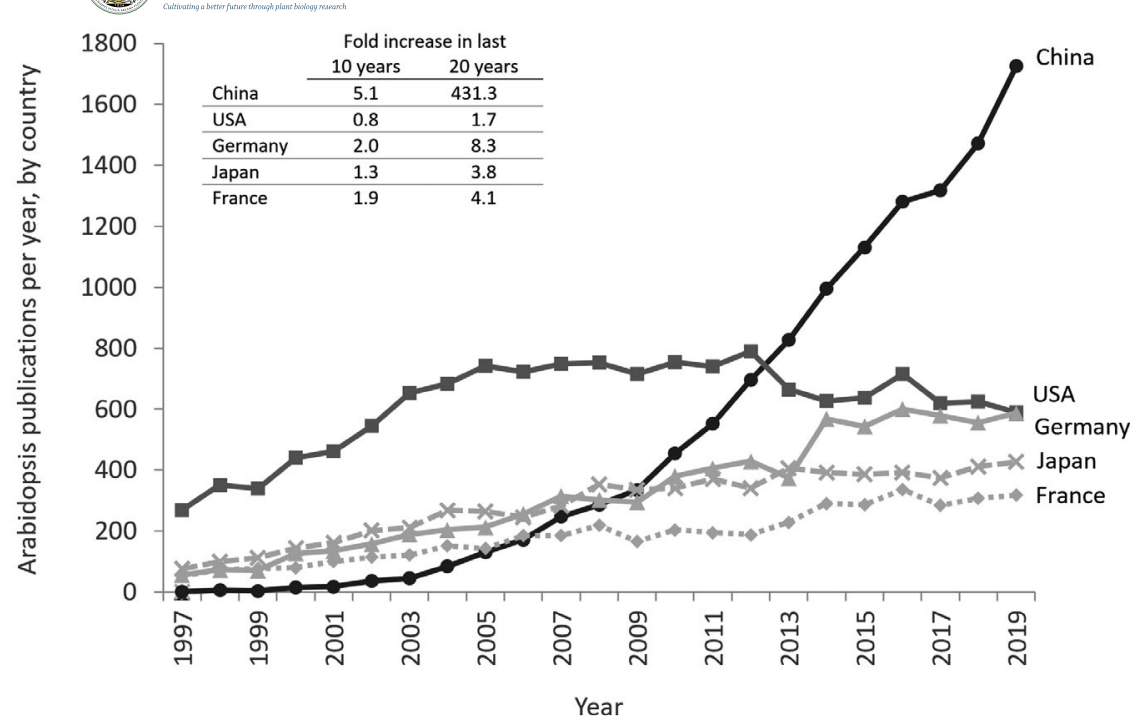

FIGURE 3 Papers published in PubMed journals with Arabidopsis in the Title/Abstract since 1997. Globally these countries have the highest number of publications in 2019. The following term was used in the PubMed search box: Arabidopsis[Title/ Abstract] AND COUNTRY AND ("journal article"[Publication Type] OR "review"[Publication Type]) AND YEAR[DP]

Kingdom publishes around 200 Arabidopsis papers per year and there is £8M in annual 'Responsive mode' Government funding for "Arabidopsis research" yet this represents a reduction in funding, so the situation is not as healthy as in previous years. However, other countries have low to no funding in research specifically dedicated to Arabidopsis, yet have a positive opinion toward research in this area, for example, "In Brazil even though there is virtually no such funding programs towards Arabidopsis, the number of institutions using Arabidopsis in their research is growing each year. We are seeing a gradual increase in the usage of Arabidopsis as a model plant for molecular and genetic studies due to its power as an easily manipulated model system to investigate gene functions." Similarly in India, although there is no earmarked financial support for Arabidopsis research from the Government, scientists can compete for grants dedicated for basic science and many projects are regularly funded on Arabidopsis exclusively; "many more projects use Arabidopsis as a system to validate genes from crop plants. Consequently, the overall quality of publications.......has improved considerably."

Therefore, despite a general admission that there is movement toward more applied research, it is encouraging that many country representatives are positive about the state of Arabidopsis research in their home country. This is exemplified by a response from Belgium; "....plant scientists feel an increasing pressure from funding agencies, universities, and research institutes to focus on more applied research aspects. This being said, it is likely that Arabidopsis will remain a major tool to generate and test hypothesis even in applied research projects." Globally, Arabidopsis clearly remains a critical experimental model for understanding "how plants work," which will lead to technological advances and knowledge increases that feed into applied projects in a variety of crop plants.

\section{5 | MOVING TOWARD THE FOURTH ROADMAP}

The following broad recommendations were included in the third decadal roadmap (Lavagi et al., 2012):
- Build a predictive model of an Arabidopsis plant from its molecular parts

- Build the International Arabidopsis Informatics Consortium, an international informatics and data infrastructure

- Exploit the wealth of natural variation that exists in Arabidopsis to further our understanding of adaptation and evolution

- Establish an effective knowledge exchange pipeline from the laboratory to the field and vice versa

- Deepen international cooperation and coordination

It is gratifying that progress has been made in each of these areas, yet work remains to be done. At the end of this period we now understand much more about the molecular and biochemical events that control how a plant grows and senses its environment. However, there remain significant gaps in our knowledge, including a lack of understanding of the complex linkages between available 'omic data sets or the more simple knowledge of how plants sense many of their required nutrients. Improvements in this area are needed to build a fully predictive model that is accurate across time. Fortunately, there is an acknowledgment that bioinformatics training and the development of digital infrastructures are key for the future in depth analysis of Arabidopsis-derived datasets.

The loss of funding for Araport was disappointing for the community and, although its key activities have been picked up by TAIR, the BAR and the Genome Context Viewer, efforts are needed to ensure that community resources have longevity. This requires the integration of international infrastructures, particularly between Western and Eastern hemispheres. In some areas international cooperation is excellent, such as in the coordination of conference planning, yet elsewhere it can be improved. These challenges include, but are not limited to, implementation of effective mechanisms of data sharing, cultural and language differences, and availability of global funding initiatives.

With this update, MASC calls on all Arabidopsis researchers to consider areas for inclusion in the next decadal roadmap. We expect participation from long-time community leaders, such as 
the North American Arabidopsis Steering Committee (NAASC), and collaborators from the United States, Germany, and Japan. We also expect that there will be contributions toward decadal priorities from a broader group of MASC members, especially those representing countries with significant and increasing Arabidopsis research, such as China or India. The positive sense of East-West collaboration that was felt by those who attended ICAR2019 in Wuhan was a promising beginning to these discussions.

\section{6 | POSSIBLE AREAS FOR INCLUSION IN THE NEXT DECADAL ROADMAP}

- What are the strategies that might be used to build globally sustainable digital infrastructures to support the integration of multiomic datasets?

- How can both the data and metadata from complex multi-omic experiments be collated and shared for the benefit of the wider community in order to feed into translational pipelines?

- How can we integrate mechanistic and quantitative genetic insights to enable plant acclimation to vastly different climates, within a very short time period?

- How can the community build internationally cohesive and diverse collaborative teams of scientists to answer important questions in plant science?

Over the next year, these ideas will be developed and will coalesce during discussions at a MASC-supported discussion session at ICAR2021 in Seattle. The roadmap will be launched and published prior to ICAR2022 in Belfast and will hopefully lead in the planning of community-driven projects over the coming decade.

\section{ACKNOWLEDGMENTS}

GP is supported by UKRI-BBSRC grant GARNet2020 (BB/ M004376/1) SMB is partially funded by an HHMI Faculty Scholar Fellowship. BU acknowledges support of his work by The Scientific and Technological Research Council of Turkey (TÜBITAK) (Grant No: 118Z137).

\section{AUTHOR CONTRIBUTIONS}

GP and NP conceived the manuscript, GP, NP, SB, and BU contributed to the manuscript. Members of Multinational Arabidopsis Steering Committee (MASC) provided background content.

\footnotetext{
ENDNOTES

${ }^{1}$ http://arabidopsisresearch.org/index.php/en/publications

${ }^{2}$ http://arabidopsisresearch.org/images/publications/mascreport s/1990_MASCPlan.pdf

${ }^{3}$ http://arabidopsisresearch.org/images/publications/mascreport s/2002_MASCreport.pdf
}

\section{REFERENCES}

Argueso, C. T., Assmann, S. M., Birnbaum, K. D., Chen, S., Dinneny, J. R., Doherty, C. J., Eveland, A. L., Friesner, J., Greenlee, V. R., Law, J. A., Marshall-Colón, A., Mason, G. A., O'Lexy, R., Peck, S. C., Schmitz, R. J., Song, L., Stern, D., Varagona, M. J., Walley, J. W., \& Williams, C. M. (2019). Directions for research and training in plant omics: Big Questions and Big Data. Plant Direct., 3(4), e00133. https://doi. org/10.1002/pld3.133

Cao, F. Y., Khan, M., Taniguchi, M., Mirmiran, A., Moeder, W., Lumba, S., Yoshioka, K., \& Desveaux, D. (2019). A host-pathogen interactome uncovers phytopathogenic strategies to manipulate plant $A B A$ responses. Plant J, 100, 187-198. https://doi.org/10.1111/tpj.14425

Cleary, A., \& Farmer, A. (2018). Genome Context Viewer: visual exploration of multiple annotated genomes using microsynteny. Bioinformatics, 34(9), 1562-1564. https://doi.org/10.1093/bioin formatics/btx 757

Fang, X., Wang, L., Ishikawa, R. et al (2019). Arabidopsis FLL2 promotes liquid-liquid phase separation of polyadenylation complexes. Nature, 569, 265-269. https://doi.org/10.1038/s41586-019-1165-8

Hamm, M. O., Moss, B. L., Leydon, A. R. et al (2019). Accelerating structure-function mapping using the ViVa webtool to mine natural variation. Plant Direct, 3, 1-20. https://doi.org/10.1002/pld3.147

International Arabidopsis Informatics Consortium (2019). Arabidopsis bioinformatics resources: The current state, challenges, and priorities for the future. Plant Direct, 3, 1-7. https://doi.org/10.1002/pld3.109

Laflamme, B., Dillon, M. M., Martel, A., Almeida, R. N. D., Desveaux, D., \& Guttman, D. S. (2020). The pan-genome effector-triggered immunity landscape of a host-pathogen interaction. Science, 367(6479), 763-768. https://doi.org/10.1126/science.aax4079

Lavagi, I., Estelle, M., Weckwerth, W., Beynon, J., \& Bastow, R. M. (2012). From bench to bountiful harvests: a road map for the next decade of Arabidopsis research. Plant Cell, 24(6), 2240-2247. https://doi. org/10.1105/tpc.112.096982.

Marshall, R. S., Hua, Z., Mali, S., McLoughlin, F., \& Vierstra, R. D. (2019). ATG8-binding UIM proteins define a new class of autophagy adaptors and receptors. Cell, 177(3), 766-781.e24. https://doi.org/10.1016/j. cell.2019.02.009

McWhite, C. D., Papoulas, O., Drew, K., Cox, R. M., June, V., Dong, O. X., Kwon, T., Wan, C., Salmi, M. L., Roux, S. J., Browning, K. S., Chen, Z. J., Ronald, P. C., \& Marcotte, E. M. (2020). A pan-plant protein complex map reveals deep conservation and novel assemblies. Cell, 181(2), 460-474.e14. https://doi.org/10.1016/j.cell.2020.02.049

Mergner, J., Frejno, M., List, M. et al (2020). Mass-spectrometry-based draft of the Arabidopsis proteome. Nature, 579, 409-414. https://doi. org/10.1038/s41586-020-2094-2

Miyashima, S., Roszak, P., Sevilem, I. et al (2019). Mobile PEAR transcription factors integrate positional cues to prime cambial growth. Nature, 565, 490-494. https://doi.org/10.1038/s41586-018-0839-y

Papanatsiou, M., Petersen, J., Henderson, L., Wang, Y., Christie, J. M., \& Blatt, M. R. (2019). Optogenetic manipulation of stomatal kinetics improves carbon assimilation, water use, and growth. Science, 363(6434), 1456-1459. https://doi.org/10.1126/science.aaw0046

Powers, S. K., Holehouse, A. S., Korasick, D. A. et al (2019). Nucleocytoplasmic partitioning of ARF proteins controls auxin responses in arabidopsis thaliana. Mol Cell, 76(1), 177-190.e5. https://doi. org/10.1016/j.molcel.2019.06.044

Provart, N. J., Alonso, J., Assmann, S. M., Bergmann, D., Brady, S. M., Brkljacic, J., Browse, J., Chapple, C., Colot, V., Cutler, S., Dangl, J., Ehrhardt, D., Friesner, J. D., Frommer, W. B., Grotewold, E., Meyerowitz, E., Nemhauser, J., Nordborg, M., Pikaard, C., Shanklin, J., Somerville, C., Stitt, M., Torii, K. U., Waese, J., Wagner, D., \& McCourt, P. (2016). 50 years of Arabidopsis research: highlights and future directions. New Phytologist, 209, 921-944. https://doi. org/10.1111/nph.13687 
Reiser, Leonore, Berardini, Tanya Z., Li, Donghui, Muller, Robert, Strait, Emily M., Li, Qian, Mezheritsky, Yarik, Vetushko, Andrey, \& Huala, Eva (2016). Sustainable funding for biocuration: The Arabidopsis Information Resource (TAIR) as a case study of a subscription-based funding model. Database, 2016, baw018. https://doi.org/10.1093/ database/baw018

Sullivan, A., Purohit, P. K., Freese, N. H., Pasha, A., Esteban, E., Waese J., Wu, A., Chen, M., Chin, C. Y., Song, R., Watharkar, S. R., Chan, A. P., Krishnakumar, V., Vaughn, M. W., Town, C., Loraine, A. E., \& Provart, N. J. (2019). An 'eFP-Seq Browser' for visualizing and exploring RNA sequencing data. Plant Journal, 100(3), 641-654. https://doi. org/10.1111/tpj.14468.

Togninalli, M., Seren, Ü., Freudenthal, J. A. et al (2020). AraPheno and the AraGWAS Catalog 2020: a major database update including RNASeq and knockout mutation data for Arabidopsis thaliana. Nucleic Acids Research, 48(D1), D1063-D1068. https://doi.org/10.1093/nar/ gkz925.

Van de Weyer, A. L., Monteiro, F., Furzer, O. J., Nishimura, M. T., Cevik, V., Witek, K., Jones, J. D. G., Dangl, J. L., Weigel, D., \& Bemm, F. (2019). A Species-Wide Inventory of NLR Genes and Alleles in Arabidopsis thaliana. Cell., 178(5), 1260-1272.e14. https://doi.org/10.1016/j. cell.2019.07.038.

Wang, Jizong, Hu, Meijuan, Wang, Jia, Qi, Jinfeng, Han, Zhifu, Wang, Guoxun, Qi, Yijun, Wang, Hong-Wei, Zhou, Jian-Min, \& Chai, Jijie (2019). Reconstitution and structure of a plant NLR resistosome conferring immunity. Science, 364(6435), eaav5870. https://doi. org/10.1126/science.aav5870

How to cite this article: Parry G, Provart NJ, Brady SM, Uzilday B; The Multinational Arabidopsis Steering Committee. Current status of the multinational Arabidopsis community. Plant Direct. 2020;00:1-9. https://doi. org/10.1002/pld3.248

\section{APPENDIX 1}

\section{MULTINATIONAL ARABIDOPSIS STEERING COMMITTEE}

Keith Adams, University of British Columbia, Canada; Wagner Araújo, Universidade Federal de Viçosa, Brazil; Sébastien Aubourg, INRA, France; Sacha Baginsky, Martin-Luther-Universität HalleWittenberg, Germany; Erica Bakker, TAIR, USA; Katja Bärenfaller, Federal Institute of Technology, Switzerland; Jacqui Batley, University of Western Australia, Australia; Mike Beale, Rothamsted Research, UK; Mark Beilstein, University of Arizona, USA; Youssef Belkhadir, Gregor Mendel Institute of Molecular Plant Biology, Austria; Tanya Berardini, TAIR, USA; Joy Bergelson, University of Chicago, USA; Francisca Blanco-Herrera, Universidad Andres Bello, Chile.; Siobhan Brady, University of California Davis, USA; Hans-Peter Braun, Leibniz Universität Hannover, Germany; Steve Briggs, University of California, USA; Lynette Brownfield, University of Otago, New Zealand; Maura Cardarelli, IBPM-National Research Council, c/o Sapienza University of Rome; Marcos Castellanos-Uribe, NASC Operations Manager, University of Nottingham, UK; Gloria Coruzzi, NYU Center for Genomics \& Systems Biology, USA; Maheshi Dassanayake, Louisiana State University, USA; Geert De Jaeger, VIB UGhent, Belgium; Brian Dilkes, Purdue University, USA; Colleen Doherty, North Carolina State
University, USA; Joe Ecker, Salk Institute, USA; Pat Edger, Michigan State University, USA; David Edwards, University of Western Australia, Australia; Farid El Kasmi, University of Tuebingen, Germany; Maria Eriksson, Umeå University, Sweden; Moises ExpositoAlonso, Carnegie Institution for Science and Stanford University, California, USA; Pascal Falter-Braun, Helmholtz Zentrum München, Germany; Alisdair Fernie, Max Planck Institute for Molecular Plant Physiology, Germany; Myriam Ferro, CEA, Grenoble, France; Oliver Fiehn, University of California, USA; Joanna Friesner, IAIC Assistant, University of California Davis, USA; Katie Greenham, University of Minnesota, USA; Yalong Guo, Institute of Botany, Chinese Academy of Sciences, China; Thorsten Hamann, Norwegian University of Science and Technology, Norway; Angela Hancock, MPI-Cologne, Germany; Marie-Theres Hauser, BOKU Vienna, Austria; Joshua Heazlewood, University of Melbourne, Australia; Cheng-Hsun Ho, Academia Sinica, Taiwan; Hanna Hõrak, University of Tartu, Estonia; Eva Huala, TAIR, USA; Inhwan Hwang, Pohang University of Science and Technology, South Korea; Satoshi luchi, RIKEN BRC, Japan; Pankaj Jaiswal, Oregon State University, USA; Liina Jakobson, Estonian Crop Research Institute, Estonia; Yunhe Jiang, KAUST, Saudi Arabia; Yuling Jiao, Institute of Genetics and Developmental Biology, China; Alexandra Jones, University of Warwick, UK; Yasuhiro Kadota, RIKEN CSRS, Japan; Jitendra Khurana, University of Delhi, India; Dan Kliebenstein, University of California Davis, USA; Emma Knee, ABRC Associate Director, Ohio State University, USA; Masatomo Kobayashi, RIKEN BRC, Japan; Marcus Koch, Heidelberg University, Germany; Gabriel Krouk, CNRS, France; Tony Larson, University of York, UK; Rob Last, Michigan State University, USA; Loïc Lepiniec, IJPB, INRAE Versailles, Université Paris-Saclay, France; Song Li, Virginia Tech University, USA; Claire Lurin, Institute of Plant Sciences -Paris- Saclay, France; Martin Lysak, CEITEC, Czech Republic; Steven Maere, VIB UGhent University, Belgium; Robert Malinowski, Department of Integrative Plant Biology Institute of Plant Genetics of the Polish Academy of Sciences, Poznan, POLAND; Florian Maumus, INRA, Versailles, France; Sean May, NASC Director, University of Nottingham, UK; Klaus Mayer, Helmholtz Zentrum München, Germany; David Mendoza-Cozatl, University of Missouri, USA; Isabel Mendoza-Poudereux, Global Plant Council, Spain; Blake Meyers, IAIC Director, The Donald Danforth Plant Science Center and the University of Missouri - Columbia; José Luis Micol, Universidad Miguel Hernández, Spain; Harvey Millar, University of Western Australia, Australia; Hans-Peter Mock, Institute for Plant Genetics and Crop Plant Research, Germany; Karolina Mukhtar, University of Alabama at Birmingham, USA; Shahid Mukhtar, University of Alabama at Birmingham, USA; Monika Murcha, The University of Western Australia, Australia; Hirofumi Nakagami, RIKEN CSRS, Japan; Yasukazu Nakamura, Kazusa DNA Research Institute, Japan; Luke Nicolov, UCLA, USA; Basil Nikolau, lowa State University, USA; Moritz Nowack, VIB-Ugent, Belgium; Adriano Nunes-Nesi, Universidade Federal de Viçosa, Brazil; Michael Palmgren, University of Copenhagen, Denmark; Geraint Parry, Cardiff University, UK; Nicola Patron, Earlham Institute, UK; Scott Peck, University of Missouri, USA; Ullas Pedmale, CSHL, USA; Catherine Perrot-Rechenmann, Institut Jean-Pierre Bourgin (IJPB) Versailles, France; Roland Pieruschka, 
Julich Plant Phenotyping Centre, Germany; José Pío-Beltrán, IBMCPCSIC, Spain; J. Chris Pires, University of Missouri, USA; Nicholas Provart, University of Toronto, Canada; Loïc Rajjou, AgroParisTech, France; Leonore Reiser, TAIR, USA; Sigrun Reumann, University of Stavanger, Norway; Sue Rhee, Carnegie Institution for Science and Stanford University, California, USA; Stamatis Rigas, Agricultural University of Athens, Greece; Norbert Rolland, CEA, Grenoble, France; Andres Romanowski, Fundación Instituto Leloir, Argentina; Véronique Santoni, INRA, France; Sigal Savaldi-Goldstein, Technion-Israel Institute of Technology, Israel; Robert Schmitz, University of Georgia, USA; Waltraud Schulze, University of Hohenheim, Germany; Motoaki Seki, RIKEN CSRS, Japan; Kentaro K. Shimizu, University of Zurich, Switzerland; Keith Slotkin, Donald Danforth Center, USA; Ian Small, University of Western Australia, Australia; David Somers, ABRC Director, Ohio State University, USA; Rosangela Sozzani, North Carolina State University, USA; Charles Spillane, National University of Ireland Galway, Ireland; Ramamurthy Srinivasan, National Institute

for Plant Biology, IARI, New Delhi and Sharda University, India; Nicolas Taylor, The University of Western Australia, Australia; Marcela-Karey Tello-Ruiz, CSHL, USA; Jay Thelen, University of Missouri, USA; Takayuki Tohge, RIKEN CSRS, Japan; Christopher Town, J. Craig Venter Institute, USA; Tetsuro Toyoda, RIKEN BASE, Japan; Baris Uzilday, Department of Biology, Faculty of Science, Ege University, Izmir, Turkey; Yves Van De Peer, VIB/ UGent, Belgium; Klaas van Wijk, Cornell University, USA; Philipp von Gillhaussen, Julich Plant Phenotyping Centre, Germany; Justin Walley, lowa State University, USA; Doreen Ware, CSHL, USA; Wolfram Weckwerth, University of Vienna, Austria; Julian Whitelegge, University of California, USA; Stefanie Wienkoop, University of Vienna, Austria; Clay Wright, Virginia Tech University, USA; Michael Wrzaczek, University of Helsinki, Helsinki, Finland; Misako Yamazaki, University of Zurich, Switzerland; Marcelo Yanovsky, Fundación Instituto Leloir, Argentina; Viktor Žárský, Charles University, Czech Republic; Xuehua Zhong, University of Wisconsin-Madison, USA. 